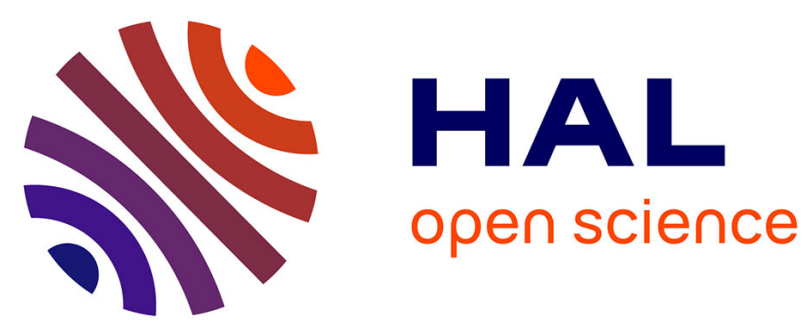

\title{
Effects of chronic gamma irradiation : a multigenerational study using Caenorhabditis elegans
}

Adeline Buisset-Goussen, Benoît Goussen, Claire Della-Vedova, Simon Galas, Christelle Adam-Guillermin, Catherine Lecomte-Pradines

\section{To cite this version:}

Adeline Buisset-Goussen, Benoît Goussen, Claire Della-Vedova, Simon Galas, Christelle AdamGuillermin, et al.. Effects of chronic gamma irradiation : a multigenerational study using Caenorhabditis elegans. 24. SETAC Europe annual meeting "Science across bridges, borders and boundaries", May 2014, Bâle, Switzerland. pp.80. ineris-01862421

HAL Id: ineris-01862421

https://hal-ineris.archives-ouvertes.fr/ineris-01862421

Submitted on 27 Aug 2018

HAL is a multi-disciplinary open access archive for the deposit and dissemination of scientific research documents, whether they are published or not. The documents may come from teaching and research institutions in France or abroad, or from public or private research centers.
L'archive ouverte pluridisciplinaire HAL, est destinée au dépôt et à la diffusion de documents scientifiques de niveau recherche, publiés ou non, émanant des établissements d'enseignement et de recherche français ou étrangers, des laboratoires publics ou privés. 


\title{
Effects of chronic gamma irradiation: a multigenerational study using Caenorhabditis elegans
}

\author{
Adeline Buisset-Goussen ${ }^{1}$, Benoit Goussen ${ }^{1-2}$, Claire Della-Vedova $^{3}$, Simon Galas ${ }^{4}$, \\ Christelle Adam-Guillermin ${ }^{1}$, Catherine Lecomte-Pradines ${ }^{1}$ \\ 1 Institut de Radioprotection et de Sûreté Nucléaire (IRSN), PRP-ENV, SERIS, Laboratoire d'ECOtoxicologie des radionucléides (LECO), Cadarache, France \\ 2 Unité Modèles pour l'Ecotoxicologie et la Toxicologie (METO), Institut National de l'Environnement Industriel et des Risques (INERIS), BP2, F-60550 Verneuil en \\ Halatte, France \\ 3 Magelis, 6 rue Frederic Mistral, 84160 Cadenet, France \\ 4 Centre de Recherches de Biochimie Macromoleculaire, CNRS UPR 1086, 34293 Montpellier cedex 5, France \\ E-mail contact: adeline.buisset@irsn.fr
}

\section{Introduction}

Emission of ionizing radiations into the environment is a natural and ubiquitous phenomenon, which may be enhanced by human activities. The environmental risk assessment of chronic exposure to ionizing radiation is currently hampered by the lack of knowledge, and hence, is often based on extrapolation from data obtained from acute exposure [1]. Indeed, most of ecotoxicological studies on ionizing radiation have focused only on partial lifecycles of organisms and on one generation, whereas it is known that pollutants acting on both survival and reproduction could also lead to phenotypic changes occurring across generations [2]. The free-living nematode Caenorhabditis elegans is a relevant biological model for studying multigenerational effects because of its short lifecycle, small size, and high fecundity, making this organism easy to culture under laboratory conditions. The aim of this study is to better evaluate the the disturbances related to chronic exposure to ionizing radiation and their possible consequences on the population.

\section{Materials and methods}

The wild-type N2 strain of $C$. elegans was used in this study. Gravid worms were randomly selected from the stock population at $t=0$. After $1 \mathrm{~h}$, the adults were removed and the released fertilized embryos were considered to be age-synchronized; these embryos represented the first generation (F0). After 4 days of exposure, the adult worms from F0 were transferred onto a new experimental unit, replaced in irradiator, and left for $1 \mathrm{~h}$ for embryo collection and preparation of the next generation (F1), as previously described for F0. The same method was again repeated to obtain the third generation (F2) and recovery generations (F1', F2'). 10 replicates were used for control of each generation and 7 replicates were used for each dose rates of each generation.

Reproduction and body length were observed daily. To monitor brood size, the worms were transferred into individual Petri dishes every day since the onset of spawning. For the measurement of body length, the nematodes were photographed using a stereomicroscope. The pictures were then analyzed with the software Image $\AA$ and a micrometer scale measure. Growth parameters (initial length, maximal length, and growth rate) were obtained thanks to a Gompertz model.

External gamma irradiation was provided by a $137 \mathrm{Cs}$ source $(1.55 \mathrm{GBq}$ ), and seven dose rates (excluding the control) of $6.6,8.1,10.5,13.7,19.4,28.1$, and $42.7 \mathrm{mGy} / \mathrm{h}$ were tested. The Figure 1 presents the experimental design.

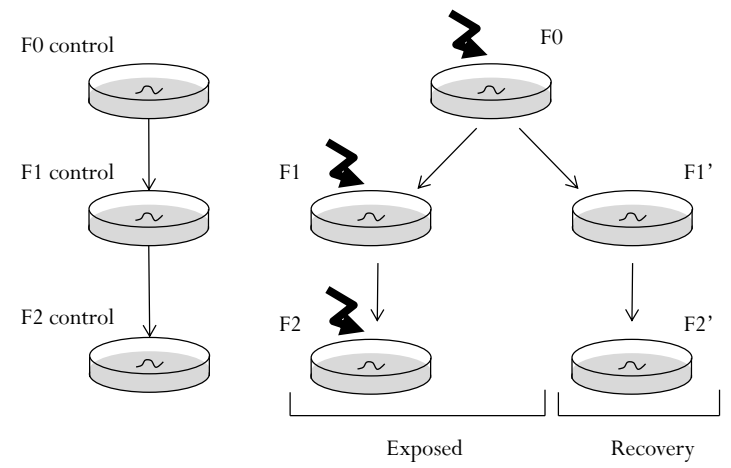

Figure 1: Exposure scenarios: F1 and F2 were continuously exposed to the same dose rate as F0 whereas F1' and F2' were placed to recovery 


\section{Results and discussion}

Whatever the generation and the exposure statuses (exposed or recovery), no significant difference was observed in the growth parameters (growth rate, minimum, and maximum length) between the control and tested dose rates.

\subsection{Decrease in the reproductive ability across generations}

As presented in Figure 2A, a significant decrease was found in the cumulated number of larvae between the first and the third generation following exposure to the highest dose rate $(42.7 \mathrm{mGy} / \mathrm{h})$. The effects on reproduction noted between these two generations could be explained by the genetic effects resulting from complex events occurring in previous generations.

\subsection{Difference between F1 and F1': transgenerational effects of parental irradiation?}

Figure $2 \mathrm{~B}$ showed that the non-exposed generation ( $\left.\mathrm{F} 1^{\prime}\right)$ laid out less number of eggs than the exposed generation (F1). These differences could be explained by the transmission of the biological effects of parental radiation exposure to the non-exposed progeny through the germline.

OF0 OF1 •F2

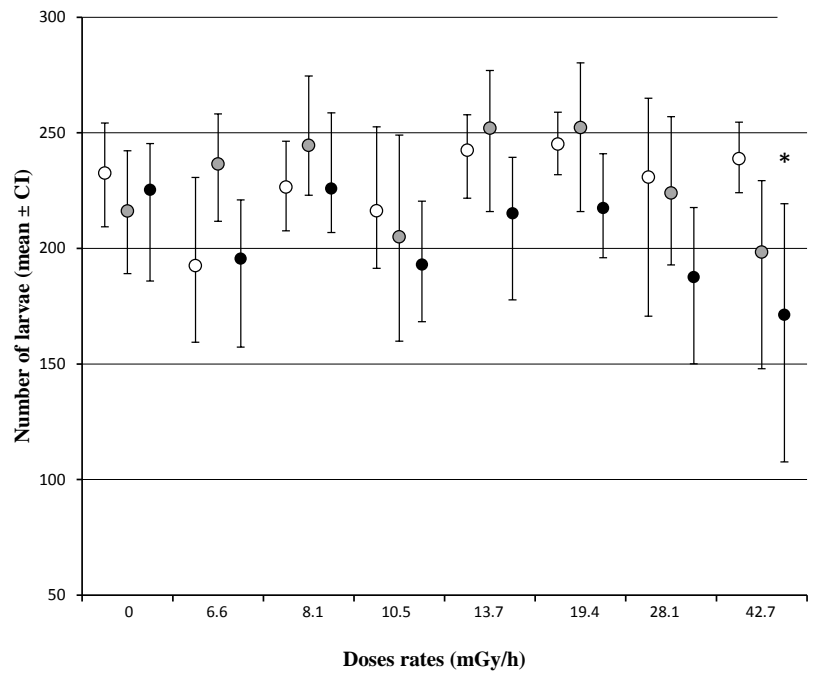

A

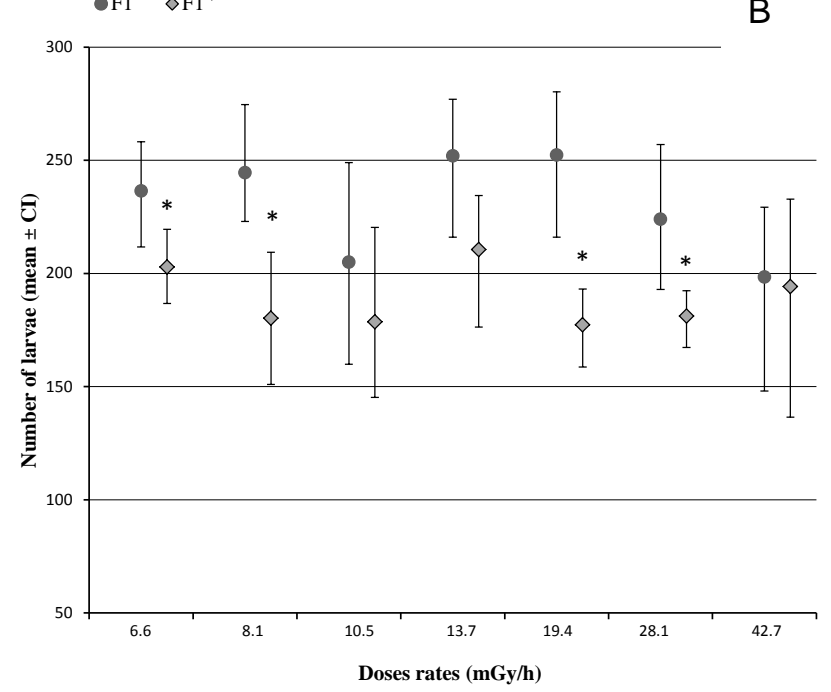

Figure 2: (A) Cumulated number of larvae in the successive generations exposed to ionizing radiations (FO, F1, and F2). Asterisk indicates significant differences between F0 and F2 generations ( $p$-value< 0.05 ). (B) Cumulated number of larvae in F1 and F1'. Dose rates for F1' correspond to parental exposure dose rates. Asterisks indicate significant difference between F1 and F1' (p-value< 0.05$)$.

\section{Conclusions}

Reproduction (cumulated number of larvae) was observed to be the most sensitive endpoint affected by multigenerational exposure to ionizing radiation. We found a significant decrease in the egg laying capacity between the first and third generations exposed to the highest dose rate $(42.7 \mathrm{mGy} / \mathrm{h})$. The results obtained revealed transgenerational effects from parental exposure in the second generation ( $\left.F 1^{\prime}\right)$. Using these results on reproduction, molecular and cellular effects of chronic exposure to ionizing radiations on germline are examined to better understand the mechanisms underlying the observed effects.

\section{References}

[1] Garnier-Laplace J., Gilek M., Sundell-Bergman S., \& Larsson C.M. 2004. Assessing ecological effects of radionuclides: Data gaps and extrapolation issues. Journal of Radiological Protection 24(4 A):A139-A155.

[2] Dutilleul M, Lemaire, L., Réale, D., Lecomte, C., Galas, S., Bonzom, J.M. 2013. Rapid phenotypic changes in Caenorhabditis elegans under uranium exposure. Ecotoxicology:1-7.

\section{Acknowledgments}

The authors thank the Envirhom-Eco research program supported by the French Institute for Radioprotection and Nuclear Safety (IRSN). 